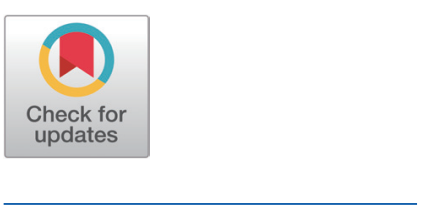

Received: Jul 28, 2021

Revised: Oct 13, 2021

Accepted: Oct 25, 2021

\#These authors contributed equally to this work.

${ }^{*}$ Corresponding author

Sam Churl Kim

Institute of Agriculture and Life Science, Gyeongsang National University, Jinju 52828 , Korea.

Tel: +82-55-772-1947

E-mail: kimsc@gnu.ac.kr

Copyright (c) 2021 Korean Society of Animal Sciences and Technology. This is an Open Access article distributed under the terms of the Creative Commons Attribution Non-Commercial License (http:// creativecommons.org/licenses/by$\mathrm{nc} / 4.0 /$ ) which permits unrestricted non-commercial use, distribution, and reproduction in any medium, provided the original work is properly cited.

ORCID

Young Hoo Joo

https://orcid.org/0000-0002-3041-623X

Seung Min Jeong

https://orcid.org/0000-0002-2589-8529

Dimas Hand Vidya Paradhipta

https://orcid.org/0000-0001-7233-469X

Hyuk Jun Lee

https://orcid.org/0000-0003-4766-6742

Seong Shin Lee

https://orcid.org/0000-0002-4872-3705

Jeong Seok Choi

https://orcid.org/0000-0002-6586-186X

\title{
Improvement of conception rate on Hanwoo; The key hormones and novel estrus detector
}

\author{
Young Ho Joo ${ }^{1 \#}$, Seung Min Jeong ${ }^{2 \#}$, Dimas Hand Vidya Paradhipta ${ }^{2,3}$, \\ Hyuk Jun Lee ${ }^{2}$, Seong Shin Lee ${ }^{1}$, Jeong Seok Choi ${ }^{2}$, Hyeon Tak Noh², \\ Hong Hee Chang ${ }^{1,4}$, Eun Joong $\mathrm{Kim}^{5}$ and Sam Churl Kim ${ }^{1,2,4 *}$ \\ ${ }^{1}$ Institute of Agriculture and Life Science, Gyeongsang National University, Jinju 52828, Korea \\ ${ }^{2}$ Division of Applied Life Science (BK21Four), Gyeongsang National University, Jinju 52828, Korea \\ ${ }^{3}$ Department of Animal Nutrition and Feed Science, Universitas Gadjah Mada, Yogyakarta 55281, Indonesia \\ ${ }^{4}$ Department of Animal Science, Gyeongsang National University, Jinju 52828, Korea \\ ${ }^{5}$ Department of Animal Science, Kyungpook National University, Sangju 37224, Korea
}

\section{Abstract}

Two field experiments were conducted to improve the conception rate of Hanwoo cow. The first experiment aimed to investigate the physiological condition of Hanwoo cows on estrus, including metabolic profiles and body condition score (BCS). The second experiment investigated the effect of a novel estrus detector on the artificial insemination (Al) conception rate for Hanwoo cows. For the first experiment, 80 Hanwoo cows ( $2.5 \pm 0.10$ of parity), approximately one month before estrus, were housed in 16 pens and offered the experimental diets twice daily with free water access. The BCS were recorded, and blood was collected from the jugular veins just before Al. The collected blood was used to measure physiological conditions, such as metabolite and hormone levels. For the second experiment, each cow was equipped with a neck-mounted estrus detector collar, which had a sensor connected through the internet. Approximately one month before estrus, three hundred sixty Hanwoo cows (2.4 \pm 0.21 of parity) were assigned into groups with or without W-Tag collar treatments. The animals were managed the same as in the first experiment. The pregnancy rate reached $55 \%$ in the first experiment. The concentration of luteinizing hormone $(\mathrm{LH})$ was higher $(p<0.012 ; 1.56$ vs. $1.08 \mathrm{ng} / \mathrm{mL}$ ) in cows that were not pregnant (NPG) than in cows that were pregnant (PG) after AI. The BCS and other concentrations of metabolites and hormones in the blood were not different in both NPG and PG cows. The ranges of estrogen, $\mathrm{LH}$, and follicle-stimulating hormone for PG cows were 11.9 to $39.0 \mathrm{pg} / \mathrm{mL},<0.25$ to $1.98 \mathrm{ng} / \mathrm{mL}$, and $<0.50$ to $0.82 \mathrm{ng} /$ $\mathrm{mL}$, respectively. In the second experiment, cows with the estrus detector had lower days open ( $p<0.001 ; 78.1$ vs. 84.8 d), insemination frequency ( $p<0.001 ; 1.26$ vs. 2.52 ), and return of estrus ( $p<0.001 ; 70.9$ vs. $79.1 \mathrm{~d}$ ) than those in cows without the estrus detector. In conclusion, the present study indicated that lower LH concentration just before Al potentially increased the pregnancy rate of Hanwoo cows. Furthermore, the application of estrus detectors to Hanwoo cows could improve the conception success rate for Al.

Keywords: Artificial insemination, Conception rate, Estrus detector, Hanwoo cow, Luteinizing hormone 
Hyeon Tak Noh

https://orcid.org/0000-0002-2489-071X

Hong Hee Chang

https://orcid.org/0000-0003-1690-9692

Eun Joong Kim

https://orcid.org/0000-0002-5962-6994

Sam Churl Kim

https://orcid.org/0000-0003-3105-0118

Competing interests

No potential conflict of interest relevant to

this article was reported.

\section{Funding sources}

This research was supported (Project No. 315019-05-2-SB030) by IPET (Korea Institute of Planning and Evaluation for Technology in Food, Agriculture, Forestry and Fisheries), and Ministry of Agriculture, Food and Rural Affairs, Korea.

Acknowledgements

Not applicable.

Availability of data and material Upon reasonable request, the datasets of this study can be available from the corresponding author.

Authors' contributions

Conceptualization: Chang $\mathrm{HH}$, Kim EJ, Kim SC.

Data curation: Joo YH, Jeong SM.

Formal analysis: Joo YH, Jeong SM.

Methodology: Joo YH, Jeong SM, Paradhipta

DHV, Lee HJ, Lee SS, Choi JS, Noh HT.

Software: Joo YH, Jeong SM.

Validation: Joo YH, Jeong SM, Paradhipta DHV, Lee HJ, Lee SS, Choi JS, Noh HT.

Investigation: Joo YH, Jeong SM, Paradhipta DHV, Lee HJ, Choi JS, Noh HT, Chang $\mathrm{HH}$, Kim EJ, Kim SC.

Writing-original draft: Joo YH, Jeong SM, Paradhipta DHV.

Writing-review \& editing: Joo YH, Jeong SM, Paradhipta DHV, Chang HH, Kim EJ, Kim SC.

Ethics approval and consent to participate This research has been approved by administration office of Gyeongsang National University, Jinju, Korea under the animal care and use guidelines of the Animal Research Unit (GNU-191011-E0050)

\section{INTRODUCTION}

Artificial insemination (AI) is the most common breeding method for Hanwoo cattle in Korea [1]. On 2019, total of Hanwoo cattle were reported around 3.48 million, which 90\% of Hanwoo cows applied AI technique for breeding program [1]. In the field, the breeder usually follows visual symptoms (i.e., animal behavior) to predict the time of ovulation, such as mounting, restlessness, noisiness, pink and swollen vulva, or decrease milk production [2,3]. Thus, the success of AI commonly depends on the breeder's ability to identify the visual symptoms of cows during their estrus period [4]. During estrus, the visual symptoms of cows are caused by an increase of estrogen and a decrease in progesterone [3]. Follicle-stimulating hormones (FSH) and luteinizing hormones (LH), secreted by the pituitary gland, together stimulate the development of follicular growth and trigger ovulation [5]. Estrogen, FSH, and LH are the hormones with the highest concentrations when $\mathrm{AI}$ is performed on cows [3,5]. However, the key hormone related to the success rate of AI for Hanwoo cows in the field is unclear. Even though AI can be conducted based on the visual symptoms displayed by Hanwoo cows, it does not always lead to optimal timing. Errors regarding estrus detection could decrease the conception rate from AI, and lead to increased cost [6].

In general, the optimal time for AI is approximately $12-15$ hours after the first appearance of estrus symptoms $[7,8]$. However, the detection of the first estrus symptoms is difficult to ascertain accurately. For this reason, instruments to detect estrus period onset in cows have been developed and tested in previous studies [8,9]. The use of an estrus detector in the field can help breeders detect the first appearance of estrus, which can lead to an increase in conception rate from $\mathrm{AI}[3,6]$. Recently, there are several methods to predict the first appearance of estrus, such as observing body and vaginal temperature, rumination time, lying behavior, mounting and standing-to-be-mounted behavior, and physical activity [8,9,10]. From 2010 to 2018, pedometer and neck mounted collar were the most studied tools of estrus detection by previous researchers [8,9]. In the principle, the differences in physical activity between non-estrus and estrus cows can predict the first appearance of the estrus period $[7,8]$. However, limited studies have been conducted to evaluate the effect of an estrus detector on $\mathrm{AI}$ success rate for Hanwoo cows in the field.

Therefore, two field trials were conducted in the present study to determine the key hormones and the effect of a novel estrus detector on Hanwoo cow AI conception rate.

\section{MATERIALS AND METHODS}

The animal procedures for the first and second experiments were approved by the administration office of Gyeongsang National University, Jinju, South Korea, under the animal care and use guidelines of the Animal Research Unit (GNU-191011-E0050).

\section{First experiment}

\section{Animal, diet, and management}

This experiment was conducted at Hapcheon Livestock Industry Cooperatives (Hapcheon, Korea). A total of 80 Hanwoo cows ( $2.5 \pm 0.10$ of parity; $40 \pm 3$ mo of age), approximately a month before estrus, were assigned for this experiment. Five cows were randomly housed in each pen $(5 \mathrm{~m} \times$ $10 \mathrm{~m})$. The pens were installed with a feeder on a slatted floor. The animals were fed a total mixed ration (TMR) that was formulated with iso-nitrogenous and iso-caloric nutrients to supply the nutrient requirements of cows (Table 1), in accordance with the Korean Feeding Standards for Korean Cattle by the National Livestock Research Institute [11]. The ingredients and chemical compositions of TMR are presented in Table 1. During maintenance, the basal diet $(3 \mathrm{~kg})$ with rice 


\begin{tabular}{|c|c|c|}
\hline Item & Basal diet & Rice straw \\
\hline \multicolumn{3}{|l|}{ Ingredients (\%) } \\
\hline Protein concentrate & 8.00 & \\
\hline Corn flakes & 6.00 & \\
\hline Soybean meal & 3.50 & \\
\hline Soybean hulls & 5.00 & \\
\hline Italian ryegrass silage & 7.00 & \\
\hline Corn silage & 6.00 & \\
\hline Annual rye straw & 10.0 & \\
\hline Tall fescue hay & 7.00 & \\
\hline Brewers grain & 10.0 & \\
\hline Spent mushroom & 20.0 & \\
\hline Tofu by-product & 4.50 & \\
\hline Rice bran & 3.00 & \\
\hline Premix ${ }^{1)}$ & 0.20 & \\
\hline Microbes & 0.20 & \\
\hline Molasses & 3.00 & \\
\hline Water & 6.60 & \\
\hline \multicolumn{3}{|c|}{ Chemical composition (\% DM) } \\
\hline Dry matter & $60.8 \pm 1.22^{2)}$ & $87.2 \pm 0.51$ \\
\hline Crude protein & $13.1 \pm 0.31$ & $4.88 \pm 0.24$ \\
\hline Ether extract & $5.43 \pm 0.21$ & $2.02 \pm 0.18$ \\
\hline Crude ash & $10.6 \pm 0.76$ & $12.4 \pm 0.58$ \\
\hline Neutral detergent fiber & $33.6 \pm 0.38$ & $61.1 \pm 0.55$ \\
\hline Acid detergent fiber & $11.5 \pm 0.67$ & $46.5 \pm 0.36$ \\
\hline
\end{tabular}

${ }^{11}$ One kilogram contained the following: vitamin A, 450,000 IU; vitamin $\mathrm{D}_{3}, 300,000 \mathrm{IU}$; vitamin $\mathrm{E}, 25,000 \mathrm{IU}$; vitamin $\mathrm{K}_{3}, 500 \mathrm{mg}$; vitamin $\mathrm{B}_{1}, 200 \mathrm{mg}$; vitamin $\mathrm{B}_{12}, 13 \mathrm{mg}$; pantothenic acid, $40 \mathrm{mg}$; niacin, $30 \mathrm{mg}$; biotin, $20 \mathrm{mg}$; folic acid, $10 \mathrm{mg}$; $\mathrm{FeSO}_{4}, 3,500$ mg; $\mathrm{CoSO}_{4}, 150$ mg; $\mathrm{CuSO}_{4}, 4,500$ mg; $\mathrm{MnSO}_{4}, 2,000$ mg; ZnSO $4,2,500$ mg; I, 400 mg; Se (Na), 150 mg.

${ }^{2)}$ Mean \pm SD.

straw $(1.5 \mathrm{~kg})$ were fed twice daily at 08:00 $\mathrm{h}$ and 17:00 $\mathrm{h}$. Water was offered ad libitum during the experimental period. About $500 \mathrm{~g}$ of TMR was sub-sampled to analyze its chemical compositions.

For conducting AI, the onset of estrus from Hanwoo cows was predicted based on visual appearance such as mounting, restlessness, noisiness, and so on. After detecting the onset of estrus, AI was carried out about 12 to $15 \mathrm{~h}$ later. At the onset of the estrus period, just before AI, the body condition score (BCS) of each Hanwoo cow was recorded according to Wildman et al. [12]. Furthermore, $10 \mathrm{~mL}$ of blood was collected from the jugular vein $3 \mathrm{~h}$ after morning feeding. Blood samples were collected in syringes and injected into tubes containing clot activator. The treated blood samples were placed in a gel separator (Vacuette Z Serum Sep Clot Activator, Greiner BioOne, Kremsmünster, Austria), and they were immediately stored on ice before delivery to the laboratory. Blood plasma samples were obtained by centrifuging blood at $969 \times \mathrm{g}$ for $15 \mathrm{~min}$ at $4^{\circ} \mathrm{C}$ (SUPRA21K, Hanil Science Industrial, Incheon, Korea) and stored at $-20^{\circ} \mathrm{C}$ until subsequent analyses. Blood plasma was used for the analyses of blood metabolites and hormones. The pregnancy status of the 80 cows studied was noted 2 months after AI. Non-pregnant cows were labeled as "NPG" and pregnant cows were labeled as "PG". 


\section{Laboratory analysis}

The sub-sampled TMR was dried at $65^{\circ} \mathrm{C}$ for $48 \mathrm{~h}$ and ground fine enough by a cutting mill to pass through a 1-mm screen (Shinmyung Electric, Gimpo, Korea), in accordance with a previous study [13]. The dry matter (DM) concentration was analyzed using a forced-air drying oven at $105^{\circ} \mathrm{C}$ for $24 \mathrm{~h}$. Crude ash (CA) was determined by a muffle furnace at $550^{\circ} \mathrm{C}$ for $5 \mathrm{~h}$. Crude protein $(\mathrm{CP})$ and ether extract (EE) were measured by the producers of Kjeldahl (method 984.13 of AOAC [14]) and Soxhlet (method 920.39 of AOAC [14]), respectively. Neutral detergent fiber (NDF; method 2002.04 of AOAC [14]) and acid detergent fiber (ADF; method 973.18 of AOAC [14]) were determined using an Ankom 200 fiber analyzer (Ankom Technology, Macedon, NY, USA).

Pregnancy diagnosis was determined using the rectal palpation method designed by Cowie [15]. Collected plasma was used to analyze the metabolite parameters consisting of blood urea nitrogen (BUN) and glucose, and the hormone parameters consisting of prolactin, estrogen, $\mathrm{LH}, \mathrm{FSH}$, and progesterone. The plasma concentration of BUN was determined using a UREA/BUN kit (Roche, Basel, Swiss). An enzymatic kinetic assay was used to determine the plasma concentrations of glucose (GLU kit; Roche). An electrochemiluminescence immunoassay (ECLIA) was used to determine the concentrations of plasma prolactin, estrogen, LH, FSH, and progesterone (ELISA kit, Roche).

\section{Second experiment}

\section{Estrus detector}

A novel estrus detector, the W-Tag estrus detector (Wuyang, Jeonju, Korea), was applied in this study. For preparation, an internet modem was installed in the cattle house. An accelerometer for the W-Tag estrus detector, using an IBSO3 model, (Ingics Technology New Taipei City, Taiwan) was installed into neck-mounted collars to record the physical activity of the cows in real-time. The physical activity of each cow was recorded as an electron volt $(\mathrm{eV})$. Using the internet of things (IoT) approach, every physical activity of the cows paired with W-Tag estrus detectors was recorded and transferred automatically into a data collector through the internet. In principle, a cow has different physical activity during the estrus period, compared to the rest of its herd [16]. Thus, the algorithm data among estrus and non-estrus cows was analyzed by a cloud server to predict the first appearance of the estrus period and the optimal time to conduct AI. Estrus status, and the optimum time for AI can be predicted using W-Tag estrus detectors which can be accessed by devices, such as smartphones or computers. The system of W-Tag estrus detection is presented in Fig. 1. The W-Tag estrus detector is recommended to be applied at $-20^{\circ} \mathrm{C}$ to $60^{\circ} \mathrm{C}$, with maximum humidity of $95 \%$.

\section{Animal, diet, and management}

An experiment was conducted from September 2019 to December 2020 at five beef cattle farms in Hapcheon, Korea. A total of 360 Hanwoo cows ( $2.4 \pm 0.21$ of parity), with varied ages and body weights, were used in this second study. Approximately one month before estrus, 100 cows were applied with W-Tag estrus detectors, and 260 cows were not applied with W-Tag estrus detectors, as a control group. Cows with W-Tag estrus detectors were randomly located among five Hanwoo farms. Five Hanwoo cows were placed in each pen $(5 \mathrm{~m} \times 10 \mathrm{~m})$. All pens were installed with a feeder on a slatted floor. Animal diet and management followed the same procedure for each beef cattle farm. The diet was formulated based on Korean Feeding Standards to maintain the health of the animals [11]. Water was offered ad libitum in all farms during the experimental period. 


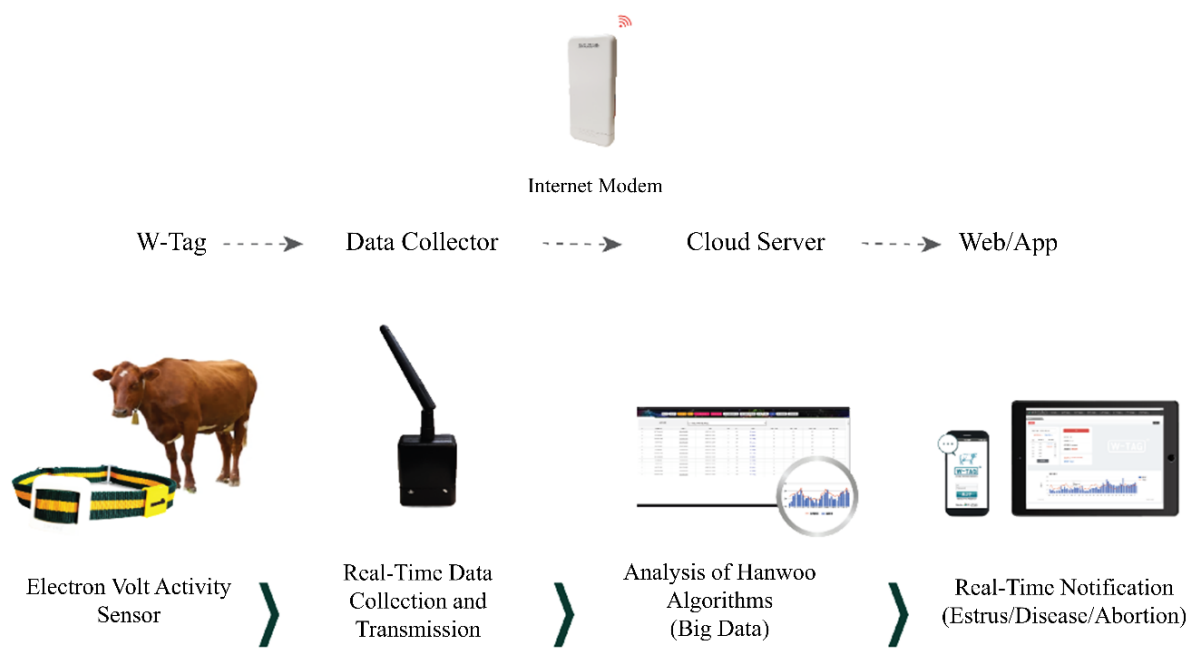

Fig. 1. The module of W-Tag estrus detector system for Hanwoo cows. W-Tag, neck-mounted collars; Web/ APP, website or mobile application (Second experiment).

\section{Laboratory analysis}

The days open, insemination frequency, and onset of estrus were evaluated using a novel estrus detector. The days open and insemination frequency were examined from postpartum to the time before insemination. The return of estrus was examined from postpartum to the first appearance of estrus.

\section{Statistical analysis}

Data from first experiment consisting of BCS, metabolite profiles, and hormones were analyzed using an analysis of variance (ANOVA) by PROC ANOVA from Statistical Analysis System (SAS, version 9, Cary, NC, USA) [17]. Data from second experiment consisting of the days open, insemination frequency, and return of estrus were also analyzed using same procedure of SAS in the first experiment. Mean separation was analyzed using Tukey's test and significant differences were declared at $p<0.05$.

\section{RESULTS AND DISCUSSION}

\section{First experiment}

The ingredients and chemical compositions of basal diet and rice straw are shown in Table 1. Concentrations of DM, CP, and NDF from the basal diet and rice straw were $60.8 \%, 13.1 \%$, and $33.6 \%$ and $87.2 \%, 4.88 \%$, and $61.1 \%$, respectively. Of the 80 Hanwoo cows, 44 cows were reported to be pregnant after AI (Table 2). The pregnancy rate was $55 \%$ after AI in the first experiment. Several studies have reported that the pregnancy rate of a beef cow from AI is around $40 \%$ to $60 \%[5,18]$. Thus, the result of the pregnancy rate in the present study was in the range of the average rate. A varied pregnancy rate for Hanwoo cows in the field could be caused by the different competences of farmers for detecting the estrus period and different methods of estrus synchronization $[5,18]$.

Just before AI, the concentration of LH was higher in NPG cows than in PG cows (1.09 vs. $1.56 \mathrm{ng} / \mathrm{mL}$; respectively, $p=0.012$ ). Similar $\mathrm{LH}$, estrogen, and FSH also reached their peaks during the estrus period $[2,3,5,6]$. However, the concentrations of both hormones before AI did 
Table 3. Range value of body condition score and physiological condition of metabolites and hormones form Hanwoo cows with pregnancy status in the first experiment $(n=44)$

\begin{tabular}{lccc}
\hline \multicolumn{1}{c}{ Item } & Minimum & Maximum & Standard deviation \\
\hline $\begin{array}{l}\text { Body condition score } \\
\text { Metabolites }(\mathrm{ng} / \mathrm{mL})\end{array}$ & 2.00 & 4.00 & 0.337 \\
$\quad$ Blood urea nitrogen & 5.80 & 19.3 & \\
Glucose & 22.0 & 66.0 & 11.83 \\
Hormones & & & \\
Prolactin $(\mathrm{ng} / \mathrm{mL})$ & $<0.05$ & $<0.05$ & - \\
Estrogen $(\mathrm{pg} / \mathrm{mL})$ & 11.9 & 39.0 & 7.49 \\
LH $(\mathrm{ng} / \mathrm{mL})$ & $<0.25$ & 1.98 & 0.497 \\
FSH $(\mathrm{ng} / \mathrm{mL})$ & $<0.50$ & 0.82 & 0.049 \\
Progesteron $(\mathrm{ng} / \mathrm{mL})$ & 1.72 & 30.0 & 11.72 \\
\hline
\end{tabular}

$\mathrm{LH}$, luteinizing hormone; $\mathrm{FSH}$, follicle-stimulating hormone.

no differences between pregnant and non-pregnant Hanwoo cows. In another study, the blood concentrations of LH, FSH, and progesterone on Hanwoo cows during estrus varied depending on seasons. Especially, the FSH and LH concentrations were lower in the summer season, while the progesterone concentration was higher [23]. The PG cows before AI had similar concentrations of LH and FSH with other heifer breeds, such as Holstein [20]. Furthermore, in Holstein heifers, the $\mathrm{LH}$ concentration was around $1.10 \pm 0.03 \mathrm{ng} / \mathrm{mL}$ and the FSH concentration was around $0.50 \pm$ $0.01 \mathrm{ng} / \mathrm{mL}$ [20]. Furthermore, the concentrations of LH and FSH were around $1.10 \pm 0.03 \mathrm{ng} /$ $\mathrm{mL}$ and $0.50 \pm 0.01 \mathrm{ng} / \mathrm{mL}$, respectively [20]. In another beef cattle breed, $\mathrm{LH}$ concentration was around 1 to $1.5 \mathrm{ng} / \mathrm{mL}$ during prepartum and periodically increases up to $3 \mathrm{ng} / \mathrm{mL}$ after 2 weeks postpartum until period of estrus [19].

\section{Second experiment}

According to the first experiment, a failure in predicting the optimal time for AI could occur even if the breeder had pinpointed the visual symptoms of estrus. From a practical point of view, the first appearance of estrus is difficult to identify accurately. Though the concentration of LH in blood is a good indicator for proper timing for AI, collecting blood samples from a hypersensitive cow should neither be recommended nor be encouraged. Therefore, synchronizing the appropriate time for AI by obtaining information on $\mathrm{LH}$ concentration will be an extremely challenging task for farmers. For this reason, the second experiment was developed with the concept that recent technological advances may provide more accurate information on estrus-related animal behavior. In the field, an estrus detector could be applied to predict the first appearance of estrus more accurately than observing visual symptoms $[5,8,24]$. Physical activity among estrus cows and non-estrus cows could be used as an indicator for estrus [7,8]. By using a W-Tag estrus detector, the physical activity of the cow can be recorded in real-time. For example, an estrus cow presents different physical activity compared to a non-estrus cow. This can be recorded by the application of a W-Tag estrus detector (Fig. 2). The algorithm analysis of physical activity from cows from the cloud server showed that the first appearance of estrus occurred at the second hour of the 21st day. Therefore, the optimum time for AI, using W-Tag estrus detection, could be predicted to be from the 14 to 16th $\mathrm{h}$ of the 21std. The prediction time for optimal AI by W-Tag estrus detection is supported by the results of previous studies, which reported an optimum time for $\mathrm{AI}$ at 12 to $15 \mathrm{~h}$ after the first appearance of estrus $[7,8]$. The application of the W-Tag estrus detector as a novel instrument presented beneficial effects for the breeding program of Hanwoo in the present study. The days open $(p<0.001 ; 84.8$ 


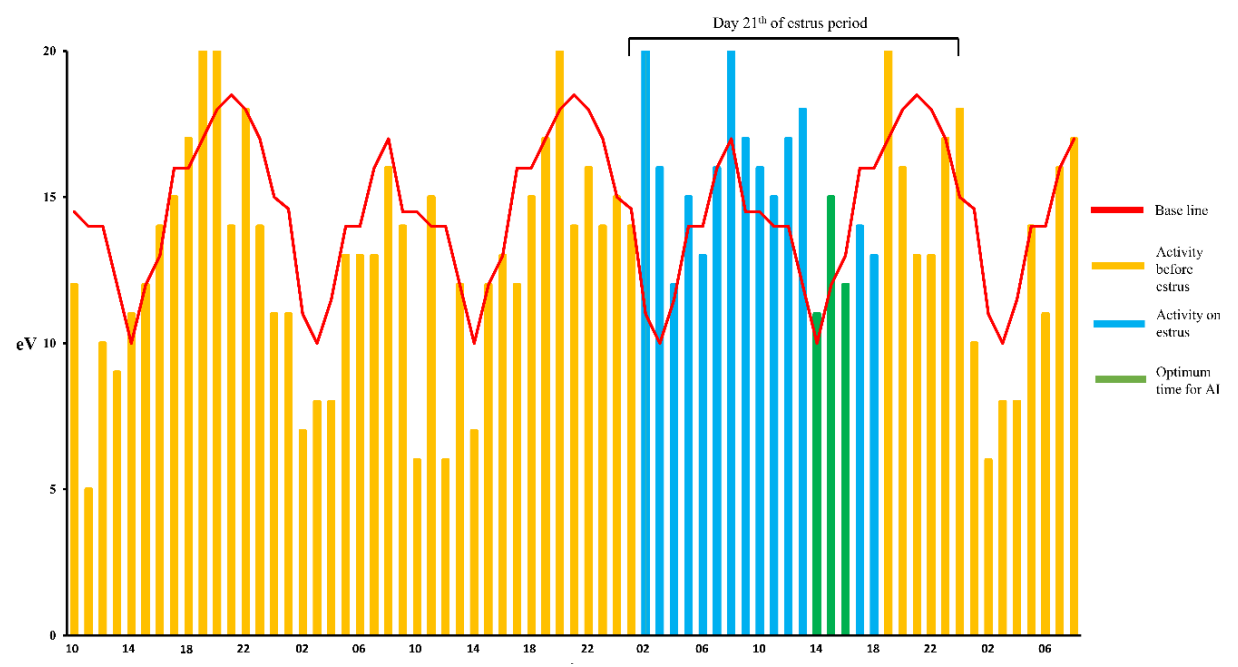

Fig. 2. Physical activity of Hanwoo cows on 19 to 21 of estrus cycle using W-Tag estrus detector. The red line as base line indicated a general physical activity of Hanwoo cows (herd). The blue bar indicated the duration of estrus in Hanwoo cows, while the green bar indicated an optimum time to conduct artificial insemination (Al) (Second experiment).

vs. $78.1 \mathrm{~d}$ ), insemination frequency ( $p<0.01 ; 2.52$ vs. 1.26 ), and return of estrus $(p<0.001 ; 79.1$ vs. 70.9 d) of Hanwoo were lower with application of the estrus detector than without application of the estrus detector (Table 4). The days open, insemination frequency, and return of estrus were improved by the application of a W-Tag estrus detector. This improved the overall conception rate of AI for Hanwoo cows.

In several cases, visual symptoms of a cow on estrus are not clearly apparent. This makes it difficult for breeders to predict when estrus begins [6,25]. Compared to observing temperature and behavior changes, observation of physical activity changes using an accelerometer had higher accuracy for predicting the first appearance of estrus [9]. The physical activity of Hanwoo cows on estrus was reported in real-time, which helped to predict precisely the first appearance of estrus and the optimum time for AI. At-Taras and Spahr [24] also reported that the application of an accelerometer to observe the physical activity of cows had a higher efficiency rate than a heat-mount detector for estrus period prediction. This provides a convincing reason for the use of an accelerometer as an estrus detector. As an upgrade, we attached a wireless sensor to the accelerometer with an IoT system to help farmers easily view the estrus status of their cows any time, from a variety of devices, as fast as possible.

Table 4. Effects of W-Tag estrus detector application on days open, insemination frequency, and return of estrus day of Hanwoo cows in the second experiment

\begin{tabular}{lccccc}
\hline \multirow{2}{*}{ Item } & \multicolumn{2}{c}{ Hanwoo cow cr) $^{1)}$} & \multirow{2}{*}{ SEM } & p-value \\
\cline { 2 - 3 } & Not use & Use & & - \\
\hline Farm (n) & 5 & 5 & - & - \\
Animal (head) & 260 & 100 & - & $<0.001$ \\
Days open (d) & $84.8^{\mathrm{a}}$ & $78.1^{\mathrm{b}}$ & & 1.209 & $<0.001$ \\
Insemination frequency & $2.52^{\mathrm{a}}$ & $1.26^{\mathrm{b}}$ & & 0.266 & $<0.001$ \\
Return of estrus (d) & $79.1^{\mathrm{a}}$ & $70.9^{\mathrm{b}}$ & & 0.648 & \\
\hline
\end{tabular}

${ }^{1)}$ Not use, cows without estrus detector; Use, cows with estrus detector

${ }^{a, b}$ Means in the same row with different superscripts differ $(p<0.05)$. 


\section{CONCLUSION}

The first experiment concluded that the concentration of LH just before AI influenced the conception rate. Therefore, a lower concentration of LH just before AI could improve the conception rate of Hanwoo cows. The second experiment concluded that the application of a W-Tag estrus detector could decrease the days open, increase the insemination frequency, and speed the return of estrus for Hanwoo cows and increase the successful conception rate of AI.

\section{REFERENCES}

1. Lee JH, Kim MH, Pyo YR. Recent Hanwoo market condition. GSnJ Focus. 2018;258:1-16.

2. Foote RH. Estrus detection and estrus detection aids. J Dairy Sci. 1975;58:248-56. https://doi. org/10.3168/jds.S0022-0302(75)84555-3

3. Fricke PM, Carvalho PD, Giordano JO, Valenza A, Lopes G Jr, Amundson, MC. Expression and detection of estrus in dairy cows: the role of new technologies. Animal. 2014;8:134-43. https://doi.org/10.1017/S1751731114000299

4. Pecsok SR, McGilliard ML, Nebel RL. Conception rates. 1. Derivation and estimates for effects of estrus detection on cow profitability. J Dairy Sci. 1994;77:3008-15. https://doi. org/10.3168/jds.S0022-0302(94)77242-8

5. Lamb GC, Dahlen CR, Larson JE, Marquezini G, Stevenson JS. Control of the estrous cycle to improve fertility for fixed-time artificial insemination in beef cattle: a review. J Anim Sci. 2010;88:E181-92. https://doi.org/10.2527/jas.2009-2349

6. Senger PL. The estrus detection problem: new concepts, technologies, and possibilities. J Dairy Sci. 1994;77:2745-53. https://doi.org/10.3168/jds.S0022-0302(94)77217-9

7. Maatje K, Loeffler SH, Engel B. Predicting optimal time of insemination in cows that show visual signs of estrus by estimating onset of estrus with pedometers. J Dairy Sci. 1997;80:1098105. https://doi.org/10.3168/jds.S0022-0302(97)76035-1

8. Roelofs JB, van Erp-van der Kooij E. Estrus detection tools and their applicability in cattle: recent and perspectival situation. Anim Reprod. 2015;12:498-504.

9. Mičiaková M, Strapák P, Szencziová I, Strapáková E, Hanušovský O. Several methods of estrus detection in cattle dams: a review. Acta Univ Agric Silvic Mendel Brun. 2018;66:619-25. https://doi.org/10.11118/actaun201866020619

10. Kyle BL, Kennedy AD, Small JA. Measurement of vaginal temperature by radiotelemetry for the prediction of estrus in beef cows. Theriogenology. 1998;49:1437-49. https://doi. org/10.1016/S0093-691X(98)00090-9

11. National Livestock Research Institute. Korean feeding standard for Korean cattle (KFS). Wanju, Korea: National Livestock Research Institute; 2007.

12. Wildman EE, Jones GM, Wagner PE, Boman RL, Troutt HF, Lesch TN Jr. A dairy cow body condition scoring system and its relationship to selected production characteristics. J Dairy Sci. 1982;65:495-501. https://doi.org/10.3168/jds.S0022-0302(82)82223-6

13. Paradhipta DHV, Joo YH, Lee HJ, Lee SS, Kim DH, Kim JD et al. Effects of inoculant application on fermentation quality and rumen digestibility of high moisture sorghum-sudangrass silage.J Appl Anim Res. 2019;47:486-91. https://doi.org/10.1080/09712119.2019.1670667

14. AOAC [Association of Official Analytical Chemists] International. Official methods of analysis of AOAC International. 18th ed. Washington, DC: AOAC International; 2005.

15. Cowie AT. Pregnancy diagnosis tests: a review. Aberystwyth, Wales: Commonwealth Agricultural Bureaux; 1948. 
16. Liu X, Spahr SL. Automated electronic activity measurement for detection of estrus in dairy cattle.J Dairy Sci. 1993;76:2906-12. https://doi.org/10.3168/jds.S0022-0302(93)77630-4

17. SAS [Statistical Analysis System] Institute. SAS/STAT user's guide. Version 9. Cary, NC: SAS Institute; 2002.

18. Lee MS, Rahman MS, Kwon WS, Chung HJ, Yang BS, Pang MG. Efficacy of four synchronization protocols on the estrus behavior and conception in native Korean cattle (Hanwoo). Theriogenology. 2013;80:855-61. https://doi.org/10.1016/j.theriogenology.2013.07.010

19. Arije GR, Wiltbank JN, Hopwood ML. Hormone levels in pre- and post-parturient beef cows. J Anim Sci. 1974;39:338-47. https://doi.org/10.2527/jas1974.392338x

20. Ronchi B, Stradaioli G, Verini Supplizi A, Bernabucci U, Lacetera N, Accorsi PA, et al. Influence of heat stress or feed restriction on plasma progesterone, oestradiol-17 $\beta, \mathrm{LH}, \mathrm{FSH}$, prolactin and cortisol in Holstein heifers. Livest Prod Sci. 2001;68:231-41. https://doi.org/10.1016/ S0301-6226(00)00232-3

21. Kwon EG, Cho YM, Choi YH, Park BK, Chung HJ, Choi NJ, et al. Effects of maternal genetic potential and parity with pre- and postpartum on body weights, body condition score and blood metabolites in Hanwoo cows. J Anim Sci Technol. 2006;48:881-8. https://doi. org/10.5187/jast.2006.48.6.881

22. Kang SS, Kim UH, Lee SD, Lee MS, Kwon EK, Jang SS, et al. Basic analysis of metabolic parameters by using metabolic profile test (MPT) for improvement breeding in Korean native cow. J Korean Soc Grassl Forage Sci. 2018;38:331-6. https://doi.org/10.5333/ KGFS.2018.38.4.331

23. Chung HJ, Yoon HI, Lee SD, Ko JS, Choy YH, Choi SB, et al. Concentration differences in $\mathrm{LH}, \mathrm{FSH}$ and progesterone secretion among seasonal changes in Hanwoo and Holstein heifers in Daegwallyeong.J Embryo Transf. 2008;23:257-61.

24. At-Taras EE, Spahr SL. Detection and characterization of estrus in dairy cattle with an electronic heatmount detector and an electronic activity tag. J Dairy Sci. 2001;84:792-98. https:// doi.org/10.3168/jds.S0022-0302(01)74535-3

25. Rorie RW, Bilby TR, Lester TD. Application of electronic estrus detection technologies to reproductive management of cattle. Theriogenology. 2002;57:137-48. https://doi.org/10.1016/ S0093-691X(01)00663-X 